\title{
A anarcoarquitetura de Gordon Matta-Clark: autonomismo político e ativismo estético
}

\section{Resumo}

Pretendemos pensar as relações entre arte, política e resistência no Contemporâneo, partindo das práticas artísticas dos anos 1960 e 1970, estabelecidas pelo arquiteto, artista performático e ativista autonomista, o estadunidense, Gordon Matta-Clark (1943-1978). Utilizaremos, especialmente, para tal empreitada os conceitos propostos por Gilles Deleuze (e Félix Guattari), notadamente em seu livro O que é a filosofia?, de "devir-revolucionário da arte", "fabulação criadora” e "atos de criação/atos de resistência”.

Palavras-chave:

Gordon Matta-Clark, ativismo estético-político, atos de criação, devir-revolucionário da arte, Gilles Deleuze 


\title{
The anarchitecture of Gordon Matta-Clark: political autonomism and aesthetic activism
}

\author{
JORGE VASCONCELLOS
}

Keywords: Gordon Matta-Clark, aesthetic and political activism, acts of creation, becoming-revolutionary of art, creative fabulation, Gilles Deleuze 
Propomos aqui pensar as relações entre arte, política e resistência, notadamente as práticas estético-políticas de um singular artista dos anos 1960/70: o estadunidense Gordon Matta-Clark (1943-1978), especialmente, o coletivo artístico fundado e por ele intitulado de Anarcoarquitetura. Pretendemos partir, em primeiro lugar, da ideia de "regimes das artes", proposta por Jacques Rancière em seu livro A partilha do sensível. Estética e Política. Segundo o pensador francês, estaríamos em grande medida dominados por práticas artísticas que se caracterizam pela múltipla heterogeneidade do sensível, chamadas por ele de regime estético da(s) arte(s), distinto dos regimes ético das imagens (emblematizado pelo pensamento metafísico de Platão) e o mimético/poético (exemplarmente conforme as concepções da filosofia da arte de Aristóteles). Para Rancière o regime estético das artes coloca o problema d'O que é o Comum? no campo ampliado das artes; ou dito de outro modo: não é mais possível na contemporaneidade pensar as artes apenas a partir das obras e das formas de realização das práticas dos artistas. Mas, isto sim, procurando pensar e realizar de que modo esse "fazer" dos artistas em nosso presente, inseridos em suas comunidades, produzem implicações éticas e ativismos sociais nas mais variadas formas de participação política.

Em segundo lugar, é preciso pensar esta inflexão entre arte, política e resistência sob uma chave interpretativa ético-estética, especialmente constituída a partir da noção proposta por Michel Foucault, elaborada sob o signo nietzschiano, de "estética da existência" e/ou "estética de si", e/ou ainda como "ontologia de nós mesmos". Isso porque ao investigarmos as relações entre arte, política e resistência, tendo como ponto de inflexão as meditações estético-filosóficas, calcadas nas ideias de um conjunto de filósofos que teceram algumas das princi- 
pais linhas de força entre os sistemas de pensamento do contemporâneo, que aqui denominaremos de Filosofia Francesa Contemporânea. Entendemos que os conceitos e as ideias, em especial, de Michel Foucault, Gilles Deleuze \& Félix Guattari, e também aquelas que apresentamos acima de Jacques Rancière, nos auxiliam decisivamente a produzir nexos de sentido em que se articulam os domínios da ética e da estética filosófica, partindo de uma rubrica que conjuga a Arte, como elaboração de projetos e constituição das práticas artísticas, e a Vida, pensada como invenção de modos de existir e produção de novas subjetividades. Tanto Foucault, quanto Deleuze e Guattari (e porque não, Jacques Rancière), nessa perspectiva tem Nietzsche como seu intercessor filosófico privilegiado.

A despeito das análises foucaultianas terem se debruçado, especialmente na derradeira fase de sua obra, em investigar os modos de vida e a subjetividade antiga greco-romana, as noções de "estética da existência" e "ontologia de nós mesmos", apenas para ficar nessas duas que de certo modo representam o mesmo campo semântico-conceitual, são de certo modo produtos de um sopro nietzschiano. Estas são, no limite, tentativas engendradas pelo pensador francês de pensar novas formas de subjetividade e novos modos de resistir aos processos de subjetivação engendrados pelos dispositivos do biopoder nas sociedades do capitalismo contemporâneo. Diríamos o mesmo em relação à concepção de modos de vida e às relações entre "máquina literária" e "nomadismo", "arte e existência", "literatura e vida" cunhadas por Deleuze e Guattari. Aqui Nietzsche também se faz presente.

Em Nietzsche, as relações entre ética e estética/arte e vida, remetem à ideia, apropriada de Píndaro pelo filósofo alemão, do "Tornar-se quem se é". Escrever é, de algum modo, tornarmo-nos quem já somos. Todavia, este processo do "tornar-se" deve, necessariamente, ser transformador. É preciso que nos entreguemos aos encontros, aos devires, para afirmar em nós, o que somos. "Tornar-se quem se é" constitui-se paradoxalmente na ideia de que para se chegar a ser o que se é, há de se combater o que já se é. Trata-se, no limite, de escrita de si. Essa ideia foi apropriada tanto por Foucault - as análises da constituição de si mesmo para a (re)construção da subjetividade, enquanto obra de arte - e por Deleuze - escrever não teria seu fim em si mesmo, precisamente porque a vida não é algo pessoal, ou antes, o objetivo da escrita é o de levar a vida ao estado de uma potência não pessoal, à impessoalida- 
de criativa e transformadora. Em suma, nesse ponto destacase o papel desses filósofos - Nietzsche, Foucault, Deleuze \& Guattari, além do próprio Jacques Rancière - na constituição de um pensamento da arte. Um pensamento da arte que articula a prática artística ao ativismo social, tal qual se faz possível notar nas intervenções urbanas produzidas outrora por Gordon Matta-Clark.

E ainda, entendemos que pensar radicalmente as relações entre arte e política de modo autonomista; e que aqui se diga que esse autonomismo por nós defendido nada tem a ver com a problemática da "autonomia da arte", mas, sim, com a ideia e a prática política de rotunda recusa radical à forma-Estado e às formas de subjetivação do capitalismo congnitivo. Falamos, isto sim, de anarquismos contemporâneos. Desse modo, recortamos, em nosso entender, uma das mais significativas experiências e práticas artísticas dos anos 1960/70, aquela que foi realizada por Matta-Clark em Nova Iorque, no bairro do Soho. Essas experiências e práticas estético-políticas a denominaremos de lutas revolucionárias!

Entretanto, essas lutas revolucionárias não se configuravam como a cartilha revolucionária típicas dos anos 1960-70, isto é, aquela que orientava que fazer a revolução se daria a partir da tomada do aparelho de Estado, da chegada ao poder constituído para construir doravante uma nova forma de sociabilidade. Tratava-se, isto sim, de viver existencialmente, a partir de um Comum (como Jacques Rancière o formula), fazendo nascer uma forma radical de devir-revolucionário da arte (tal qual o propõe Gilles Deleuze e Félix Guattari), que se constitui por intermédios de fabulações criadoras, partindo de atos de criação, que são, ao fim e ao cabo, atos de resistência aos dispositivos do biopoder (conforme Michel Foucault).

Essas formas de resistências não poderiam ser dissociadas de um vigoroso processo de reconstituição subjetiva, uma ressubjetivação radical, ao qual Matta-Clark engendrou a partir de suas práticas artísticas. Esses experimentos estéticos políticos matta-clarkianos nos anos 1960-1970, como dissemos, nos fazem repensar a noção clássica de política. Logo, em alguma medida, trata-se de repensar a própria noção do que é a política.

Não obstante, nossa principal referência e, principalmente, nossa principal amizade no pensamento e nosso intercessor privilegiado para tal empreitada em pensar a obra de Matta-Clark, será a ideia formulada por Gilles Deleuze \& Félix Guattari, especialmente em seu livro $O$ que é a filosofia? (mas já 
presente de forma embrionária em outras obras deleuzianas) de "devir-revolucionário", que acrescentamos "da arte" (conceito este articulado às ideias de "fabulação criadora" e "atos de criação/atos de resistência”). Mas, então, nos perguntamos: o que é propriamente um devir-revolucionário da arte para Gilles Deleuze (e Félix Guattari)?

A ideia de um "devir-revolucionário da arte" está presente, mesmo que de modo subjacente, em toda e qualquer obra de arte, e também nas práticas dos artistas que possam ser chamados de radicais. Nessa concepção de pensamento, a arte não responde ao chamado da doxa, do senso comum e, principalmente, dos clichês. Ela, isto sim, clama pelo diferente, pelo heterogêneo e pelo múltiplo. Essa arte radical teria como um de seus objetivos, e sentido, retirar-nos de nossa zona de conforto, confrontar-nos diante do caos, sem, contudo, deixar de traçar meios de nos fazer escapar às armadilhas da vida-fascista; produzir linhas de fuga, que nos faça resistir aos modelos predeterminados pela forma-Estado... resistir aos microfascismos da vida cotidiana. Nessa concepção estética ou pensamento da arte, que de fato é um amálgama de arte e política, aspira-se simultaneamente às mais radicais e (im)possíveis das experiências estéticas, às mais radicais das experiências políticas; e mais, à invenção de modos de vida não-fascistas.

No que aqui é denominado de "devir-revolucionário da arte", o artista evoca suas potências criadoras ao invocar as potências transformadoras de um povo que não está de antemão dado, de um povo que esta por vir, um povo que "ainda" não existe (e pode não vir a existir enquanto tal), um povo que não-há... Este "povo por vir" é um dos processos constitutivos do que poderíamos chamar de uma estética-política deleuziana. Sob essa perspectiva, há um conceito da obra deleuziana a partir do qual podemos pensar as relações entre arte, política e resistência. Este conceito é denominado pelo filósofo de fabulação, mais precisamente, "fabulação criadora".

Diríamos que aqui, na perspectiva bergsoniana, estamos ainda assentados no plano da conservação e da lembrança. A meditação sobre o fabulatório ainda estaria partindo do empírico, tendo a inteligência e a imaginação a chancelá-lo. Não estaríamos diante da novidade radical que deveria ser proposta por toda e qualquer forma de produção artística. Isso é justamente o que propõe a fabulação criadora, como um operador conceitual ao enfrentamento do problema da criação artística. Deleuze o diz explicitamente: "A fabulação criadora nada tem a 
ver com uma lembrança mesmo amplificada, nem com um fantasma. Com efeito, o artista, entre eles o romancista, excede os estados perceptivos e as passagens afetivas do vivido" (DELEUZE, 1992, p. 222). Estamos, então, diante de um novo conceito. O conceito bergsoniano de "função fabuladora", de uma certa maneira, ainda é refém das formas da matéria, do empírico e de processos recognitivos. Em contrapartida, o conceito deleuziano de "fabulação criadora" abandona a empiricidade, sem deixar de fazer um elogio ao sensível, pois, se ainda se trata da conservação, esta é conservação do que é próprio à sensibilidade: as sensações constituídas em blocos. Isto somente pode ser pensado se e somente se, deleuzianamente falando, estiver aí configurada uma leitura do tempo em seu estado puro. Por isso que a arte é, justamente, o que se conserva, o que se conserva em si. Mesmo que o material do qual um objeto de arte é feito se esvaneça, ainda assim, o que faz dele arte se conservará. Daí toda arte se tornar um monumento; daí toda arte ser, ao fim ao cabo, fruto do tempo em seu estado puro.

Deleuze possui uma dívida com Henri Bergson em relação a este termo. O autor de Le bergsonisme operou um deslocamento de sentido no conceito de "função fabuladora", formulado por Henri Bergson em As duas fontes da moral e da religião, o qual possuía em seu sentido primeiro um papel operativo no intuito de pensar as relações entre forças sociais, crenças, imaginação e constituição de mitos. Deleuze o transformou em “fabulação criadora”. Nosso filósofo modificou não só o sentido do conceito originário proposto por Bergson. Mais que isso, em Deleuze, a função fabuladora transformou-se em fabulação criadora, como dissemos, fazendo bem mais, obviamente, que uma mera modificação de nomenclatura. Em Bergson, a função fabuladora enseja a possibilidade de lermos como no seio de determinadas sociedades chamadas de tradicionais se instauram as práticas da criação fabulatória e mitológica; assim como, nas sociedades modernas, este conceito bergsoniano enseja, por exemplo, pensar a produção romanesca e teatral.

Com essa torção no conceito bergsoniano, Deleuze introduziu um poderoso operador para pensarmos a arte em sua relação com a política.

Em seus livros, A imagem-tempo - segundo dos volumes dedicados ao cinema - e O que é a filosofia?, este escrito com Félix Guattari, Deleuze elabora com mais rigor o conceito de "fabulação criadora". No conceito em questão, temos esta ideia-força bem delimitada, da relação ente arte e conserva- 
ção, que pode ser definida/resumida com a premissa: "O que a arte faz, antes de tudo, é conservar” (DELEUZE, 1992). Porém, essa conservação não se estabelece exclusivamente no plano da matéria. Em Deleuze, a conservação se faz no plano virtual, mais precisamente falando, no plano do tempo.

Retomando. Então diríamos que na relação possível entre povo e revolução, este não é "um povo que lá está" ou que fora "dado" pelo artista em sua obra. Este povo dado como pronto a ser liderado, sensibilizado não é aquele que está em jogo no conceito de fabulação criadora. O que está sendo constituído é, de fato, um povo que está por chegar... um povo por vir. Esse é o caráter político-revolucionário de toda e qualquer arte. Sob esse aspecto, poderíamos exemplificar esse procedimento investigativo da estética deleuziana com o cinema, como o próprio Gilles Deleuze destacou, no seu $A$ imagem-tempo, livro que aponta para a gênese do conceito de fabulação criadora. No livro em questão, o filósofo, à guisa de analisar o cinema moderno, chega à obra do cineasta brasileiro Glauber Rocha, na qual está delineado este que é "o povo que falta". Diríamos aqui, talvez, os mais radicais filmes políticos já realizados. No texto, o filósofo, destaca o papel de reconfiguração de mitos proposto pelo autor de Deus e o diabo na terra do sol: "É assim que vemos Glauber Rocha destruir de dentro dos mitos [...]. Resta ao autor a possibilidade de se dar 'intercessores', isto é, de tomar personagens reais e não fictícias, mas colocando-as em condições de 'ficcionar' por si próprias, de 'criar lendas', 'fabular'”(DELEUZE, 1990, p. 264). Deleuze continua sua análise, mostrando que esses mitos constituídos pela cinematografia política glauberiana é um processo fabulatório, uma forma de fabulação criadora, na qual: "A fabulação não é um mito impessoal, mas também não é ficção pessoal: é uma palavra em ato, um ato de fala pelo qual a personagem nunca para de atravessar a fronteira que separa seu assunto privado da política, e produz, ela própria, enunciados coletivos" (DELEUZE, Idem, p. 264).

No entanto, as ideias de "devir-revolucionário da arte" e de "fabulação criadora" somente fazem sentido se pensadas a partir dos atos de criação dos artistas, em suas proposições estético-políticas e em suas práticas de ativismo social. O que seria então propriamente um ato de criação? Deleuze define o próprio pensamento como um conjunto de atos de criação. Criar é realizar atos que se materializam no bojo de uma Ideia; seja esta ideia gestada em ciência, filosofia ou arte. No caso da arte, essa Ideia é uma construção que se faz no jogo de forças entre aquele que é propriamente o do material, do qual esta 
prática é delimitada, e aquilo que dá um sentido ilimitado a este mesmo material. Isso porque a prática do fazer artístico extrapola a materialidade, reinventando os suportes, modificando-os, fazendo do próprio ato de criar uma prática intensiva e vital. Esses atos de criação, contudo, nessa perspectiva que defendemos, a partir de Deleuze \& Guattari (e também de Foucault e Rancière) são, necessariamente, atos de resistência. Resistir por intermédio de intervenções, performances. Resistir por intermédio de coletivos e grupelhos. Resistir, recusando, muitas vezes, o mercado de arte, produzido a/na periferia desses mercados, fazendo-os, quem sabe, explodir.

Enfim, grosso modo, estas são algumas das relações que se podem estabelecer, no plano conceitual, entre as noções propostas por Deleuze \& Guattari para "devir-revolucionário da arte", "fabulação criadora" e "atos de criação/atos de resistência”.

Dito isso, defendemos que o pensamento da arte deleuziano, irrigado pela perspectiva dos regimes das artes de Rancière e da problemática da estética de si foucaultiana, pode ser denominado de uma estética a um só tempo materialista e vitalista, deve ser pensado como um esforço em articular arte, política e resistência. Esse pensamento da arte conjuga arte e política às formas de resistências aos poderes instituídos, e ainda: arte e vida, ética e estética, modos de existência e práticas políticas. Nessa concepção estético-política, o artista, ao produzir seus monumentos, não o faz obedecendo às orientações e às intenções de sua consciência, ou mesmo, estaria ele subordinando este fazer a devaneios e arroubos de processos imaginativos, mesmo os inconscientes. Ele, o artista, constitui sua prática criativa, cunhando para si novas maneiras de viver, simultaneamente a este criar, sujeitando-se à violência de forças que lhe são exteriores, abrindo-se aos devires... aos devires imperceptíveis. Estes, a violências das forças do defora e os devires imperceptíveis, o impede de se fazer sujeito absoluto. Isto é o que seria próprio da arte: afastar-se do absoluto e inventar-se singularmente. Entretanto, em outra medida, essas forças do de-fora e os devires imperceptíveis o faz enfrentar o caos, recusando, assim, a opinião, o bom senso e seu correlato estético: os clichês.

*

Gordon Matta-Clark traçou um percurso interessante e singular, um dos mais emblemáticos das artes visuais dos anos 1960-70, pois, com suas práticas vigorosas, como veremos, en- 


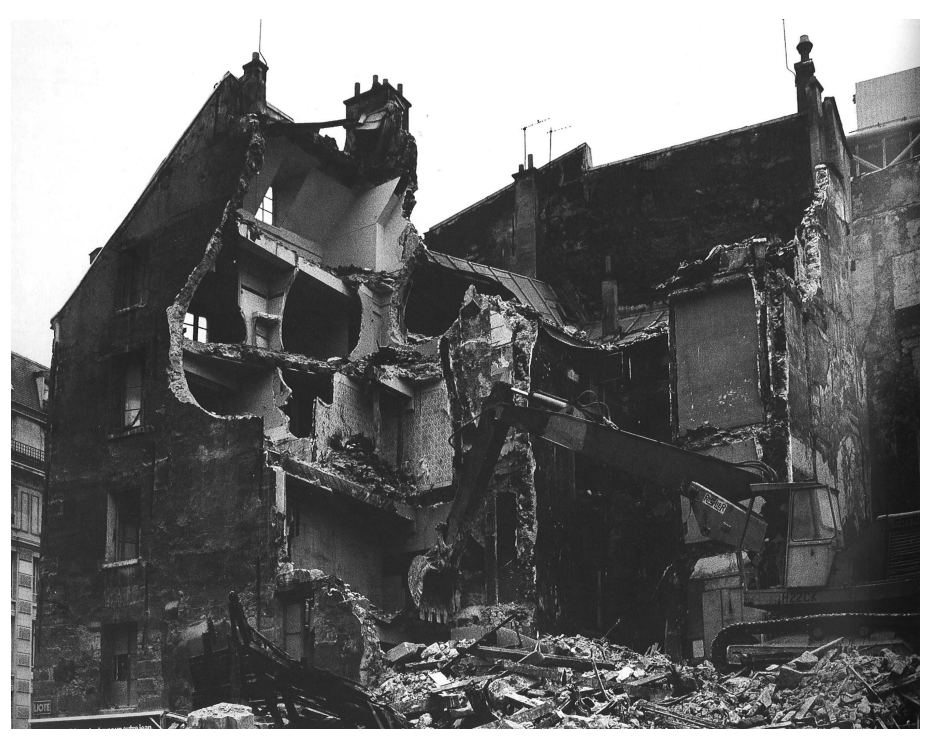

frentou aqueles que seriam clichês destacados nas chamadas artes contemporâneas. Filho de um importante pintor surrealista chileno, Roberto Matta, com uma estadunidense; nasceu em Nova Iorque, tendo cursado arquitetura em sua graduação na Cornell University, em Ithaca - localidade nova-iorquina. Seria neste período, já em fins dos anos sessenta, que se aproximou de dois artistas que se tornariam fundamentais à sua formação estética e política: Dennis Oppenheim e Robert Smithson. Participou de um workshop que definiria, então, sua trajetória: o Earth Art. Desse encontro Matta-Clark criou uma obra intensa e prolífica que articulou preocupações arquitetônicas, relacionando arte e cidade, ativismo político e práticas artísticas... até sucumbir, ainda muito jovem, aos 34 anos, em 1978 de um câncer.

A despeito de sua morte prematura, destacamos que os experimentos estéticos e a política da arte praticada por Matta-Clark, como suas ações autonomistas e suas intervenções urbanas desenvolvidas na cidade de Nova Iorque, no bairro do Soho - então em completa decadência imobiliária - em meio aos idos 1960 e 1970, mostra que o artista nova-iorquino em suas ocupações em prédios abandonados, cissuras em edifícios, grafitagens em muros e veículos, rupturas em paredes de casas, praticava uma forma, então nova, de luta revolucionária. Essas lutas constituem-se como práticas de pensamento e práticas políticas, novas maneiras de fazer política, segundo entendemos. Essas práticas políticas podem, em certa medida, 


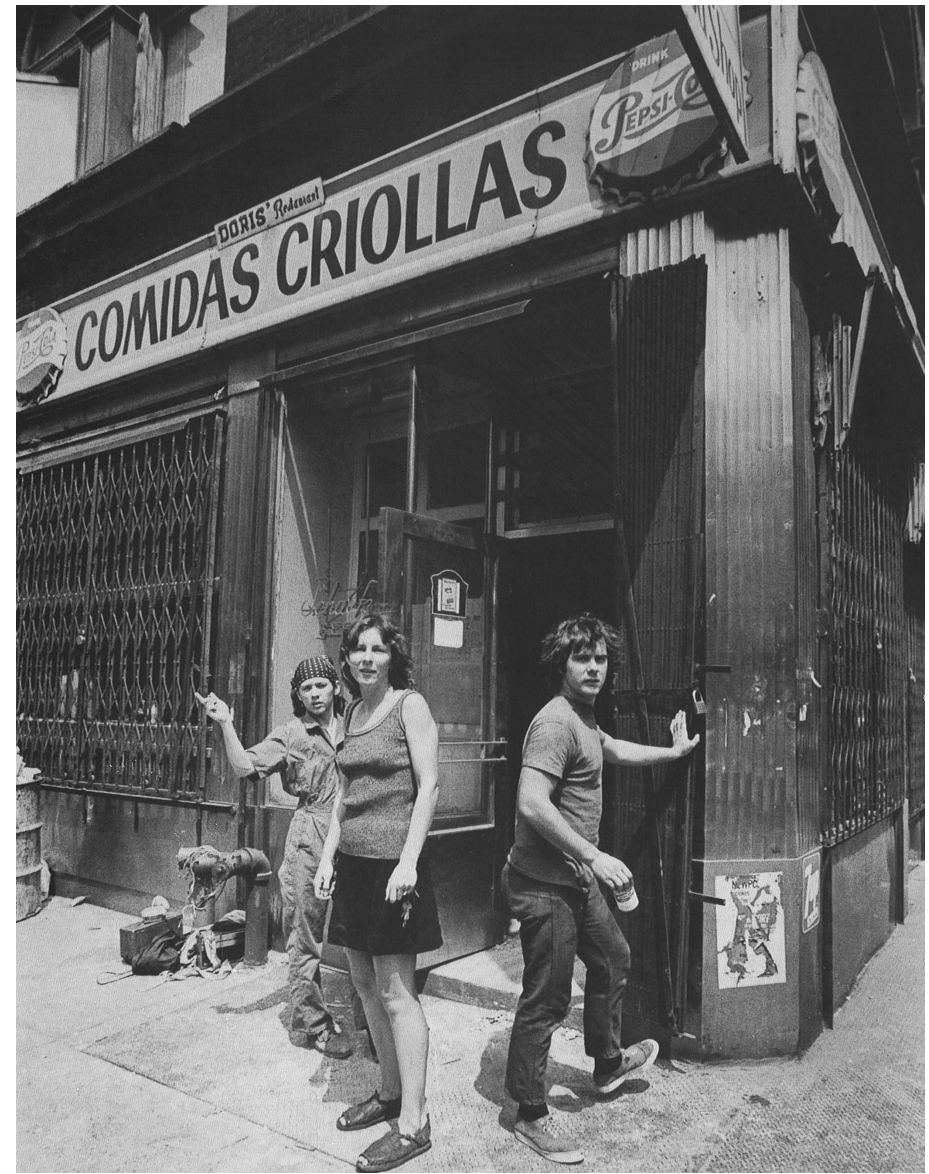

ser chamadas de uma espécie de anarquia coroada, à moda de Antonin Artaud ${ }^{1}$, como forma contemporânea de autonomismo político libertário e ativismo estético nomádico.

As ações de Gordon Matta-Clark partiram e derivaram da crítica radical à arquitetura e ao urbanismo das grandes metrópoles do capitalismo contemporâneo (em especial à sua Nova Iorque), às intervenções urbanas nos bairros periféricos nova-iorquinos, passando pelo ativismo comunitário por meio de intervenções artísticas nestas mesmas comunidades, até, enfim, à criação e consolidação desses procedimentos estéticos e políticos por intermédio do coletivo Anarcoarquitetura, palavra-síntese-intensiva de suas práticas ético-políticas

Matta-Clark foi inovador àquele momento ao se articular a um grupo de artistas que ocupou um restaurante semi-abandonado para ali desenvolver práticas não só estéticas, mas,
Figura 2

Esta imagem retrata Matta-Clark, com duas colaboradoras, na porta do 'Food'. Nova Iorque, 1971. 
também happenings, intervenções, cursos e atividades com a comunidade que cercava as imediações do Food - Comidas Criollas $^{2}$, o restaurante-oficina-criativa de arte e de intervenção política. Ele, Matta-Clark estava aberto a todas as formas de insubordinação aos poderes constituídos, deslocando-se de práticas assumidamente pedagógica-políticas - ao ensinar os jovens desocupados o fazer da carpintaria e noções básicas de edificação para que estes ocupassem e se instalassem em prédios abandonados, então completamente desvalorizados da periferia nova-iorquino - até práticas nomádicas e formas de deriva no tecido urbano da cidade: produzindo intervenções urbanas e práticas de grafitagem.

Matta-Clark atacava prédios abandonados quase sempre sozinho ou com alguns poucos colaboradores, todos munidos de picaretas, serras elétricas manuais para produzir cortes, fendas, cisões; todos com o intuito de retalhar o espaço construído. Essas edificações ora abandonadas, ora em estado de demolição, foram utilizadas pelo artista e por seus colaboradores como estratégia de colocar em questão não só a função social da arquitetura e as propostas urbanas modernas vigentes àquele momento nos Estados Unidos, mas, também, para problematizar por meio de ataques rigorosamente planejados, o próprio sentido das construções urbanas. Essa prática dos cortes que acabou por notabilizá-lo possuía uma característica marcante: um diálogo com uma certa efemeridade. Isso porque muitas daquelas construções seriam depois demolidas. Então, aquelas violações matta-clarkianas teriam uma curta duração, daí a necessidade de arquivar por intermédio de vários dispositivos audiovisuais - fotos e filmes - aqueles eventos e intervenções. Porém, o efeito de tempo curto que se constituía como parte do processo e da prática criativa matta-clarkiana se constitui como uma estratégia estética e política, não só pela forma e pelas escolhas como foram realizadas àquele momento, e também, do modo como se deram se deram as intervenções nos prédios prestes a serem demolidos, ou mesmo aqueles que estavam em completo estado de abandono. Essa estratégia pode melhor ser observada, especialmente, nas intervenções de rua que nosso artista produziu nos anos 1970. Citemos algumas delas:

1. a abertura do restaurante Food, na rua Prince (1971), espaço privilegiado para desenvolvimento de performances, happenings e improvisações artísticas, além, de servir de abrigo e acolhimento a inúmeros homeless que perambulavam à deriva pela então inóspita Nova Iorque; 
2. o ativismo comunitário contido na proposta e na prática do que o artista denominou de Open house (1971), uma espécie do que aqui chamaríamos de "casa-valise", utilizada na forma de um contêiner com rodas em permanente deslocamento pela cidade, produzindo uma real deriva pelo tecido urbano de Nova Iorque;

3. e o Freshair (1972), que consistiu em uma intervenção-happening na qual um carrinho que transportava duas pessoas de cada vez por um passeio pelas ruas, sendo que o inusitado e crítico era, justamente, o fato desses passageiros derivarem pela cidade vestidos com máscaras conectadas a tubos de oxigênio.

Esses são alguns exemplos das práticas estético-políticas matta-clarkianas. Ressaltamos também além desses procedimentos algumas proposições estético-políticas do artista, como por exemplo - Por que cortar edifícios?

Ao desfazer um edifício, há muitos aspectos das condições sociais contra os quais me posiciono: primeiro, libertar de um estado de reclusão o que sempre esteve precondicionado, não apenas por necessidade física, mas também por uma indústria pródiga em construir caixas urbanas e suburbanas como contexto seguro para a vida de consumidores passivos e isolados - espectadores virtualmente cativos (MATTA-CLARK, 2010, p. 176).

Matta-Clark denota claramente neste desenvolvimento à proposição do por que cortar edifícios? sua filiação ao situacionismo: criar situações com fins a problematizar/agindo acerca do modo de vida das sociedades do capitalismo contemporâneo, privilegiando o ataque ao consumismo e à suposta passividade do indivíduo urbano, engolido pela esfera urbana massificadora. Para isso: criar situações. Matta-Clark foi um situacionista. No entanto, lemos essas palavras matta-clarkianas em outra chave.

Entendemos Matta-Clark e suas práticas artísticas como uma forma de autonomismo político e ativismo estético. Tratou-se de, em fins dos anos 1960 e início dos 70, realizar uma vigorosa e radical constituição de estética de si: o artista que se reinventa, que abole as leis do mercado, que produz contra a autoralidade, que diz não aos modos instituídos da arte... mas não só. Tratou-se de fazer a partir de uma prática coletiva da arte - o coletivo Anarcoarquitetura - de engendrar lutas políticas nas quais fazer arte deixaria de ser o processo único e individualizante de um criador inspirado. Não! Tratar-se-ia de 
construir dispositivos que levariam a arte e suas práticas a um modo de invenção coletiva da vida cotidiana, de produção de vida comunitária, especialmente no bairro do Soho nova-iorquino, habitat de Matta-Clark. Colocar a arte como problema! Proposição matta-clarkiana, partindo do ponto de vista de que a cidade é bem mais que o tema central do urbanismo e da arquitetura, mas isto sim, a construção política da vida em comum: a construção do Comum. A obra de Matta-Clark, desse modo, colocou a própria ideia de política (da arte) em perspectiva. Diz o próprio Matta-Clark:

Todos temos uma política. Não vejo como alguém pode ter a consciência da, digamos, política da arquitetura. A arquitetura é, afinal, uma das mais complexas conquistas da humanidade, envolvendo economia, governo, cultura, técnica etc. em todos os níveis, tanto idiossincráticos como consensuais. A política da arquitetura eventualmente reduz tudo ao problema da avaliação, avaliar que tipos de coisas necessitam ser esclarecidas para que eu possa distinguir entre o que está disponível em termos de espaço aproveitável... (...) Esta é uma das atitudes que a política da arquitetura adota e que é inerente à tradição das máquinas (2010, p. 163).

Essa política da arquitetura mencionada acima por MattaClark pode ser pensada, em termos de Jacques Rancière, como uma política da arte. Os dispositivos que colocam em cheque a especulação imobiliária e as formas de ocupação do espaço urbano nas grandes cidades; as formas coletivas de autoria compartilhada e horizontal formulada pelo artista e por seus colaboradores no Anarcoarquitetura; a deambulação e a deriva como forma de resistência aos poderes instituídos... Matta-Clark coloca-se claramente naquele estatuto o qual Rancière designou de regime estético das artes. E mais, suas práticas artísticas podem ser chamadas a plenos pulmões de práticas artísticas contemporâneas. Essas práticas, em alguma medida, produziram um contundente ataque a arte moderna (CF. WALKER, 2009).

Problematizar a política seria, de fato, então, colocá-la em outras bases. Talvez não seja mais, como se fez urgência nos anos 1980-1990 tecer o fio que relacionava e ligava, fundamentalmente, política e ética; mas, retomar o rumo da nau e articu- 


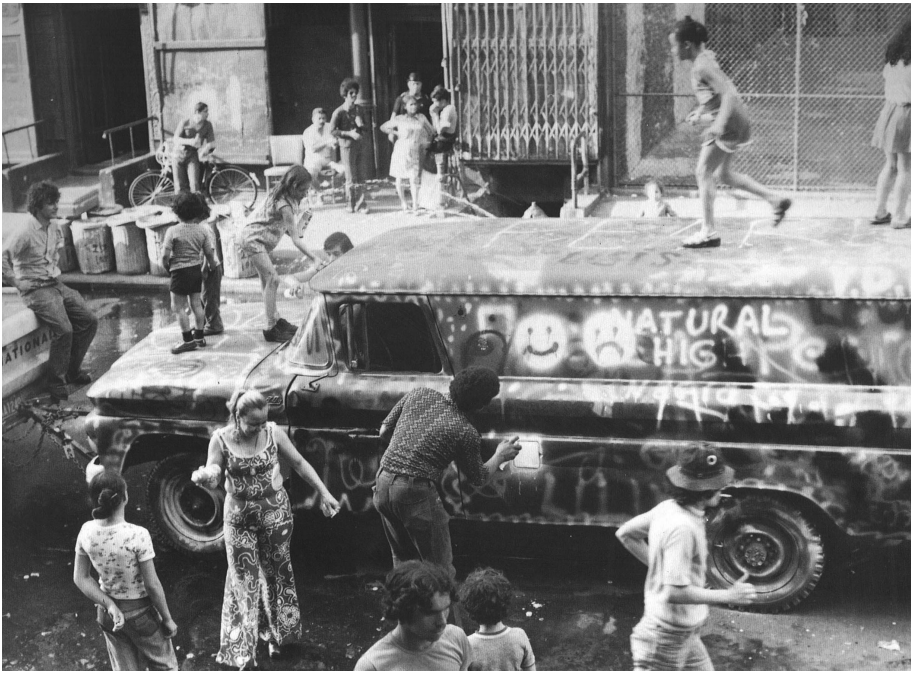

lar vigorosamente, agora, também, política e arte. Ou ainda, pensar a política como um campo aberto às experimentações. Experimentações/experiências de ações coletivas fundadoras de novas possibilidades ao existir... Política hoje, no contemporâneo, talvez nada mais seja que inventar novas subjetividades em deriva, isto é, constituir processos biopolíticos de resistência aos poderes instituídos, sejam eles processos globais e coletivos, ou processos de refundações de si mesmo.

O político é o mais alto momento da ética, mas, também, processo singular de constituição estética de si. O político em Michel Foucault (mas, particularmente em Gilles Deleuze \& Félix Guattari) é a capacidade de afirmar a singularidade, toda e qualquer processo de singularização. A singularidade como potência absoluta de existir. E mais, esse processo de afirmação dos processos singulares é acolher o que é o Comum, tal qual propõe Jacques Rancière, tal como praticou Gordon Matta-Clark. Precisamente: não só buscar o espaço deste Comum, como, também, reverter as correlações de força que constituem o biopoder e suas tecnologias de docilização, disciplinarização, assujeitamento e controle.

Fazer política da diferença, politizar a estética, instaurar o campo do Comum, seja no plano macrossocietário capitalístico - não só a partir do ultrapassamento das sociedades disciplinares para as sociedades de controle (Foucault/Deleuze) e empreender lutas a partir daí - seja no plano microssocietário dos grupelhos e hordas nômades que se fazem deslizar em Zonas Autônomas Temporárias (TAZ, como Hakim Bey),
Figura 3

Esta imagem retrata Matta-Clark observando (e participando) de uma prática de grafitagem. Nova Iorque, 1973 
implicando, segundo defendemos, neste novo tipo de intelectual-ativista, aquele que pratica ações pontuais e ativismos instantâneos. Isso porque se Foucault apontou em sua obra um deslocamento fundamental de uma certa imagem de intelectual, típica da época do Esclarecimento que ele denominou de "intelectual luz" (aquele que pode ver pelo outro e iluminar doravante seus caminhos), para um intelectual público que fala em nome do outro defendendo posições humanistas e imbuído de suposta correção ética e de reputação ilibada (o caso Dreyfus); nosso filósofo apresentou o nascimento de um novo tipo de intelectual que sucederia o militante partidário que ocupou contemporaneamente o papel de intelectual luz, pelo que ele denominou intelectual específico; que sua prática de pensamento, justamente ocorre no seio das lutas das quais ele(a)s são participantes: são vários aqui os ativismos (negros - ações e práticas afirmativas, homoafetividade - movimento Queer, mulheres - pós-feminismo, etc). De nossa parte apontamos a necessidade de um intelectual de outro tipo, que temos aqui chamado de "intelectual radical". Este pensará o presente no presente, mas, pensando-o a contrapelo das leituras hegemônicas e hegemonizadoras deste mesmo presente. Trata-se de um ativismo, entretanto, de um ativismo da diferença. Trata-se de empreender lutas, mas lutas que não apenas reformem as leis do estado, na busca de bem estar e conforto para os auspícios de uma boa vida burguesa, pois é, justamente, de lutas incessantes contra a forma-estado é do que se trata. Ir à raiz e decepá-la... a forma-Estado é raiz; daí nossa luta em nome de práticas políticas-estéticas de modo rizomáticas.

O intelectual radical não é um indignado... ele não se indigna, ele se revolta-e-age... E além de ocupar, atua e reterritorializa o que foi antes desterritorializado, pois, atuação e ativismo político deve necessariamente ser radical: AÇÃO DIRETA! Gordon Matta-Clark era, de fato, um artista radical.

Dito isso, diremos para finalizar que as práticas artistas autonomistas e as intervenções urbanas desenvolvidas por Matta-Clark na cidade de Nova Iorque em meio no idos 1960 e 1970 podem ser pensadas como uma forma contemporânea de Autonomismo Político e Ativismo Estético. Entretanto, não se tratava de fazer a revolução a partir da tomada do aparelho de Estado, mas, de viver existencialmente, a partir de um Comum, uma forma radical de devir-revolucionário da arte, que se faz por intermédios de fabulações criadoras, partindo de atos de criação, que são, ao fim e ao cabo, atos de resistência. 
Tratou-se de produzir práticas político-estéticas que se constituíram como devires, como devires-revolucionários da arte.

\section{Referências}

\section{a) Bibliográficas}

DEBORD, Guy. Teoria da deriva. IN: Internacional Situacionista - Apologia da Deriva. Escritos situacionistas sobre a cidade. Paola Berenstein Jacques (org.). Rio de Janeiro: Casa da palavra, 2003, pp.87-91

BEY, Hakim. TAZ. Zona Autônoma Temporária. São Paulo: Conrad Editora do Brasil, 2011.

DELEUZE, Gilles. Cinema 2. A imagem-tempo, tr. br. de Eloisa de Araújo Ribeiro. São Paulo: Brasiliense, 1990.

DELEUZE, Gilles e GUATTARI, Félix. Mil platôs, 5 volumes. Rio de Janeiro: Editora 34, 1995. . O que é a filosofia?, tr. br. de Bento Prado Jr. e Alberto Alonso Muñoz. Rio de Janeiro: Editora 34, 1992.

FOUCAULT, M. Ditos e Escritos III. Estética: Literatura e Pintura, Música e Cinema. $2^{\stackrel{a}{a}}$ ed. Rio de Janeiro: Forense Universitária, 2006.

GORDON MATTA-CLARK, Desfazer o Espaço. Catálogo. Museu de Arte de Lima-Peru/Paço Imperial, Rio de Janeiro-Brasil, julho de 2010.

GORDON MATTA-CLARK. Editado por Corinne Diserens. 3a. Edição de 2010. Nova Iorque: Phaido Press Inc, 2003.

RANCIÈRE, Jacques. A partilha do sensível. Estética e política. Tr. bras. de Mônica Costa Netto. São Paulo: Editora 34, 2005.

VASCONCELLOS, Jorge \& CASTELO BRANCO, Guilherme. Arte, Vida e Política: ensaios sobre Foucault e Deleuze. Rio: Edições LCV/SR3-UERJ, 2010.

WALKER, Stephen. Gordon Matta-Cllark - art, architecture and the attack on modernism. New York: I. B. Tauris, 2009.

WISNIK, Guilherme. Estado Crítico. À deriva nas cidades. São Paulo: PubliFolha, 2009.

\section{b) Videográficas}

Food (1972), filme de Gordon Matta-Clark.

http://www.ubu.com/film/gmc_food.html 


\section{c) Imagens}

Imagens scanneadas do livro GORDON MATTA-CLARK. Editado por Corinne Diserens. 3a. Edição de 2010. Nova Iorque: Phaido Press Inc, 2003.

NOTAS

1. Cf. Antonin Artaud, em sua célebre novela Heliogábalo, o anarquista coroado (ARTAUD, Antonin. Oeuvres. Paris: Gallimard), fábula sobre o poder de modo radical, na figura do personagem título.

2. Ver o filme, nas referências videográficas, Food que documenta o dia a dia no restaurante-oficina.

Recebido em: 27/11/2012

Aceito em: 03/12/12 
JORGE VASCONCELLOS

jorgevasconcellos@ymail.com

Doutor em Filosofia/UFRJ. Professor do Dept ${ }^{\circ}$ de Artes e Estudos

Culturais/RAE e do Programa de Pós-Graduação em Estudos Contemporâneos das Artes/PPGCA da Universidade Federal Fluminense/UFF. Autor, em outros, de Deleuze e o Cinema (Rio: Ciência Moderna, 2006) e do Arte, Vida e Política: ensaios sobre Foucault e Deleuze (Rio: Edições LCV-UERJ, 2010). 